\title{
Nanotubes-Embedded Indocyanine Green-Hyaluronic Acid Nanoparticles for Photoacoustic-Imaging-Guided Phototherapy
}

\author{
Guohao Wang ${ }^{\dagger}$, Fan Zhang ${ }^{\dagger}$, Rui Tian ${ }^{\star}{ }^{\ddagger}$, Liwen Zhang ${ }^{\dagger}$, Guifeng Fu ${ }^{\dagger}$, Lily Yang ${ }^{\S}$, and Lei \\ $\mathrm{Zhu}^{*}{ }^{\star}$,,$\S$ \\ †State Key Laboratory of Molecular Vaccinology and Molecular Diagnostics \& Center for \\ Molecular Imaging and Translational Medicine, School of Public Health, Xiamen University, \\ Xiamen, Fujian 361005, China \\ ‡Department of Ophthalmology Second Hospital, Jilin University, Changchun, Jilin 130033, China \\ $\S$ Departments of Surgery and Radiology and Imaging Sciences, Emory University School of \\ Medicine, Atlanta, Georgia 30322, United States
}

\begin{abstract}
Phototherapy is a light-triggered treatment for tumor ablation and growth inhibition via photodynamic therapy (PDT) and photothermal therapy (PTT). Despite extensive studies in this area, a major challenge is the lack of selective and effective phototherapy agents that can specifically accumulate in tumors to reach a therapeutic concentration. Although recent attempts have produced photosensitizers complexed with photothermal nanomaterials, the tedious preparation steps and poor tumor efficiency of therapy still hampers the broad utilization of these nanocarriers. Herein, we developed a CD44 targeted photoacoustic (PA) nanophototherapy agent by conjugating Indocyanine Green (ICG) to hyaluronic acid nanoparticles (HANPs) encapsulated with single-walled carbon nanotubes (SWCNTs), resulting in a theranostic nanocomplex of ICGHANP/SWCNTs (IHANPT). We fully characterized its physical features as well as PA imaging and photothermal and photodynamic therapy properties in vitro and in vivo. Systemic delivery of IHANPT theranostic nanoparticles led to the accumulation of the targeted nanoparticles in tumors in a human cancer xenograft model in nude mice. PA imaging confirmed targeted delivery of the IHANPT nanoparticles into tumors $(\mathrm{T} / \mathrm{M}$ ratio $=5.19 \pm 0.3)$. The effect of phototherapy was demonstrated by low-power laser irradiation $\left(808 \mathrm{~nm}, 0.8 \mathrm{~W} / \mathrm{cm}^{2}\right)$ to induce efficient photodynamic effect from ICG dye. The photothermal effect from the ICG and SWCNTs rapidly raised the tumor temperature to $55.4 \pm 1.8{ }^{\circ} \mathrm{C}$. As the result, significant tumor growth inhibition and marked induction of tumor cell death and necrosis were observed in the tumors in the tumors.
\end{abstract}

\footnotetext{
*Corresponding Authors: 18604303265@163.com (R. Tian). Tel.: (+)86-592-2880642. Fax: (+)86-592-2880642. lei.zhu@xmu.edu.cn (L.Zhu).

Supporting Information

The Supporting Information is available free of charge on the ACS Publications website at DOI: 10.1021/acsami.5b12400.

Stability, size, zeta potential, cell targeting, photothermal and photodynamic properties, biodistribution, and MRI imaging are given as Supporting Information (PDF)

Author Contributions

The manuscript was written through contributions of all authors. All authors have given approval to the final version of the manuscript. Notes

The authors declare no competing financial interest.
} 
There were no apparent systemic and local toxic effects found in the mice. The dynamic thermal stability of IHANPT was studied to ensure that PTT does not affect ICG-dependent PDT in phototherapy. Therefore, our results highlight imaging property and therapeutic effect of the novel IHANPT theranostic nanoparticle for CD44 targeted and PA image-guided dual PTT and PDT cancer therapy.

\section{Graphical abstract}

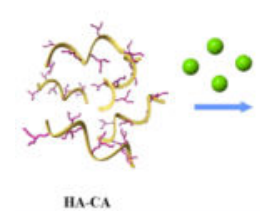

unce

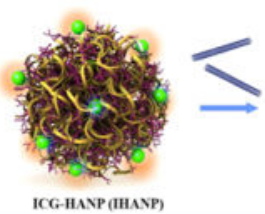

ICG-HANP(IHASP)

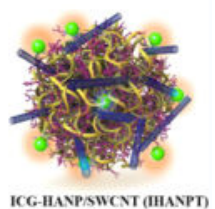

\section{Keywords}

hyaluronic acid; single wall carbon nanotube; indocyanine green; photodynamic therapy; photothermal therapy

\section{INTRODUCTION}

Phototherapy includes photothermal therapy (PTT) and photodynamic therapy (PDT). It is a promising tool for the treatment of benign and malignant tumors. ${ }^{1-3}$ Versus traditional chemotherapy and radiotherapy, laser-triggered phototherapy is an alternative tumor ablation regime. ${ }^{4-9}$ However, the selectivity and efficiency of phototherapy is limited by the relatively low photothermal conversion efficiency of photothermal agents, inadequate accumulation of phototherapy agents, and uncontrollable misalignment of the laser beam over the tumor area. ${ }^{1,10}$ Moreover, laser irradiation with different wavelengths is always required for phototherapy, because of the absorbance mismatch between photothermal coupling agents (PTCAs) and the photosensitizer (PS). ${ }^{11-14}$ In addition, because of the tissue absorption affections (especially blood, water, melanin, and fat absorptions), single continuous wave $(\mathrm{CW})$ laser at near-infrared (NIR) window $(650-1350 \mathrm{~nm})$ with the maximal penetration depth is always necessary for a satisfied phototherapy effect. ${ }^{15}$ Therefore, challenges remain in the development of effective and safe phototherapy agents.

Indocyanine Green (ICG) is an U.S. Federal Drug Administration (FDA)-approved diagnostic dye molecule ${ }^{10,16}$ that has been used for phototherapy applications, because of its strong light absorbance properties and high clinical translational potential. A variety of nanovehicles including protein cages, ${ }^{17,18}$ lipid polymers, ${ }^{19}$ and human serum albumin $(\text { HSA })^{20}$ have been developed as ICG carriers. ${ }^{16,19,21}$ While these novel agents have very high tumor ablation efficiency, the thermal/photo instability of ICG is rarely studied. Besides, the tumor accumulation of these nanocomplexes still largely depends on passive targeting via the enhanced permeability retention (EPR) effects, which may result in unsatisfied therapeutic effects for certain tumor types with lower angiogenesis. ${ }^{22,23}$

Nanomaterials have been employed as diagnosis and therapeutic tools. A variety of nanoparticles have been designed for optimizing the therapeutic strategies, improving the 
targeting ability of nanotherapeutic drug as well as enhancing the therapeutic efficacy. ${ }^{24-26}$ Particularly, hyaluronic acid (HA), which is a disaccharide polymer that naturally exists in the human body with good hydrophilicity, has been developed as a cancer theranostic agent, because of its tumor targeting ability and biocompatibility. ${ }^{27}$ Following modifications with hydrophobic moieties such as $5 \beta$-chrolanic acid, hyaluronic acid- $5 \beta$-cholanic acid conjugates self-assembled into a reel of threadlike nanoparticles (HANP) with mean diameters of $\sim 180$ $\mathrm{nm}$ and hydrophobic interior indentations. ${ }^{27}$ In addition to the EPR effects, HA can specifically bind to cluster determinant 44 (CD44), which is a cell surface protein that is highly expressed in cancer stemlike cells and lymphatic vessel endothelial hyaluronic receptor-1 (LYVE-1) that is overexpressed on many cancer tissues. ${ }^{28,29}$ The ability of active and passive tumor targeting by HANP makes it an ideal carrier for the targeted delivery of therapeutic genes, antitumor drugs, and phototherapy agents. We previously reported that single-walled carbon nanotubes (SWCNTs) could be successfully encapsulated in the hydrophobic "caves" inside the HANP for physiological stability and tumor targeting, ${ }^{30}$ which highlights the potential of this delivery system for the development of tumor targeted therapeutic agents.

In this study, we developed SWCNTs coated with ICG-coupled HANP (IHANPT) for enhanced PDT/PTT cancer treatment under photoacoustic (PA) imaging guidance (Figure 1). SWCNTs are nanoparticle carriers with PA contrasts, which are due to their strong light absorbance ${ }^{31,32}$ and high photothermal conversion efficiency. ${ }^{33-35}$ In our system, both ICG and SWCNT produced strong PA signals, which allowed monitoring IHANPT accumulation by PA imaging. Our phototherapy approach was to use a NIR laser at low power $(808 \mathrm{~nm}$, $0.8 \mathrm{~W} / \mathrm{cm}^{2}$ ) to irradiate the tumor area following CD44 targeted delivery of IHANPT into tumors, which can be degraded by intracellular hyaluronidases-1 (hyal-1), ${ }^{36}$ as demonstrated in Figure 1. We expected ICG to react with oxygen to yield singlet oxygen $\left({ }^{1} \mathrm{O}_{2}\right)$ that can induce cancer cell death. Enhanced local hyperthermia was also generated simultaneously by ICG and SWCNT for tumor photothermal therapy. Finally, tumor tissues visualized by PA imaging from IHANPT can be selectively damaged by noninvasive phototherapy. We found that the IHANPT-mediated phototherapy enhanced tumor cell ablation efficiency under lowpower laser irradiation in vitro and in vivo without tumor recurrence. Importantly, the in vivo thermal stability of ICG was pioneered to ensure that both PDT and PTT occurred. Overall, the IHANPT-mediated tumor PA imaging and ablation has shown great promise for the further development of cancer-targeted theranostic agents.

\section{EXPERIMENTAL SECTION}

\section{Reagents}

Sodium hyaluronic acid (HA, $234 \mathrm{kDa}$ ) was purchased from Lifecore Biomedical Company (Chaska, MN). Ethylenediamine (EDA), 1-ethyl-3(3-(dimethylamino)propyl)-carbodiimide (EDC), and $\mathrm{N}$-hydroxysuccinimide (NHS) were obtained from J\&K Company (Beijing, China). $5 \beta$-Cholanic acid (CA), tetrabutylammonium hydroxide (TBA), and propidium iodide (PI) were purchased from Sigma-Aldrich Co. (St. Louis, MO). Amine-PEG-amine (molecular weight $=2 \mathrm{kDa}$ ) was purchased from Shanghai Seebio Biotech (Shanghai, China). ICG-Sulfo-Osu (ICG) was obtained from Dojindo Molecular Technologies (Tokyo, 
Japan). CCK-8 assay kit and 4,6-diamidino-2-phenylindole (DAPI) were purchased from Sangon Biotech (Shanghai, China). Singlet Oxygen Sensor Green and Calcein-AM were obtained from Thermo Fisher Scientific (Waltham, MA). SCC7 (human squamous cell carcinoma cell line) was obtained from ATCC (Manassas, VA).

\section{Preparation of IHANP}

We used amine-modified ICG, and the following HANP conjugations were performed according to the procedures described previously with slight modifications. ${ }^{27}$ Briefly, 15 mmol $(1 \mathrm{~mL})$ of amine-PEG-amine $\left(\mathrm{NH}_{2}-\mathrm{PEG}-\mathrm{NH}_{2}\right)$ and $1.5 \mathrm{mmol}$ of free ICG were dissolved in anhydrous dimethylsulfoxide (DMSO) containing 3\% DIPEA. Dissolved ICG was then added dropwise into $\mathrm{NH}_{2}-\mathrm{PEG}-\mathrm{NH}_{2}$ and stirred for $40 \mathrm{~min}$ at room temperature in darkness. The synthetic $\mathrm{NH}_{2}-\mathrm{PEG}-\mathrm{ICG}$ was then purified by high-performance liquid chromatography (HPLC), using a linear gradient of $10 \%-65 \%$ acetonitrile/water $(0.1 \%$ TFA) for $30 \mathrm{~min}$ at $3.5 \mathrm{~mL} / \mathrm{min}$ and then lyophilized. Meanwhile, to dissolve hyaluronic acid (HA) in anhydrous DMSO, the HA was converted to the tetrabutylammonium salt of HA (HA-TBA), according to previously reported methods. ${ }^{27}$ The HA-TBA was then modified chemically with $5 \beta$-cholanic acid (CA) in the presence of EDC and NHS at $60{ }^{\circ} \mathrm{C}$. After $40 \mathrm{~min}, \mathrm{NH}_{2}-\mathrm{PEG}-\mathrm{ICG}$ was then added and stirred overnight at room temperature. The reaction solution was dialyzed against methanol/ultrapure water $(1: 1, \mathrm{v} / \mathrm{v})$ and ultrapure water for 4-12 h. After being lyophilized, HA-CA-ICG (IHANP) was obtained and stored at $4{ }^{\circ} \mathrm{C}$ in darkness until further use. There are approximately six ICG molecules per hundred HA subunits, as confirmed by absorbance at $780 \mathrm{~nm}$.

\section{Preparation of IHANPT}

IHANPT was obtained by simple sonication using a previously reported method with slight modifications. ${ }^{30}$ SWCNTs and IHANP (SWCNT:IHANP $=1: 4, \mathrm{w} / \mathrm{w}$ ) were added into water solution. After sonication for $60 \mathrm{~min}$ in ice bath, the product was subjected to rigorous centrifugation (10 $000 \mathrm{rpm}, 30 \mathrm{~min}$ ) at $4{ }^{\circ} \mathrm{C}$ to remove excess free SWCNTs. Supernatant was collected, and solid nanotubes were freeze-dried and weighed.

\section{SWCNTs Loading Efficiency}

To disperse SWCNT in the HANP solution, HANP and SWCNTs were dispersed in distilled water at weight ratios of 2:1, 4:1, and 10:1 and sonicated for $1 \mathrm{~h}$. Nonwrapped or loosely wrapped SWCNTs were removed by rigorous centrifugation at $10000 \mathrm{rpm}$ for $30 \mathrm{~min}$. Unloaded SWCNTs that aggregated at the bottom of the tube were collected after repeated centrifugation, followed by freeze-drying. The loading efficiency of SWCNTs was calculated using the following equation:

$$
\text { loading efficiency }=1-\frac{W_{\text {unloaded SWCNTs }}}{W_{\text {SWCNTs }}}
$$

\section{Cell Fluorescent Staining}

SCC-7 or NIH-3T3 $\left(1 \times 10^{4}\right.$ cells $)$ were seeded in six-well chamber tissue culture plates and cultured overnight. Cells were then washed with cold PBS and incubated with IHANP at 
$37{ }^{\circ} \mathrm{C}$ for $3 \mathrm{~h}$. For a blocking assay, free HANP was added to cells $30 \mathrm{~min}$ before IHANP was applied. After incubation, cells were thoroughly washed with cold PBS. Cells were finally fixed in cold ethanol (90\%) for $15 \mathrm{~min}$ at $-20^{\circ} \mathrm{C}$ and mounted with mounting medium containing DAPI for $10 \mathrm{~min}$ in darkness. Target specificity of IHANP was determined by a confocal microscope (Leica, Germany) and the excitation and emission wavelengths were set at 780 and $800 \mathrm{~nm}$ for ICG, respectively.

\section{In Vitro Photothermal Effects}

To verify the enhanced photothermal effect, aqueous solutions of HANP, free ICG, HANPT, and IHANPT were added into $1.5 \mathrm{~mL}$ Eppendorf tubes and irradiated with an $808 \mathrm{~nm}$ continuous laser at a $0.3 \mathrm{~W} / \mathrm{cm}^{2}$ for $10 \mathrm{~min}$. The entire surface of the samples was adjusted to confirm that they were covered by the laser spot. The total light dose was $90 \mathrm{~J} / \mathrm{cm}^{2}$ for in vitro photothermal therapy evaluation. The temperature and thermal images of different solutions were recorded for 10 min by a FLIR A5 camera (FLIR Systems, Inc., Wilsonville, OR, USA) and quantified with BM IR software.

\section{In Vitro Detection of Singlet Oxygen $\left({ }^{1} \mathrm{O}_{2}\right)$}

The singlet oxygen $\left({ }^{1} \mathrm{O}_{2}\right)$ was quantified with a commercial $1 \mathrm{O}_{2}$ kit, containing $2^{\prime}, 7^{\prime}$ dichlorodihydrofluorescindiacetate (DCFH-DA) that is originally nonfluorescent but fluorescent after ${ }^{1} \mathrm{O}_{2}$ oxidation. ${ }^{33}$ To verify the $1 \mathrm{O}_{2}$ generation potency, aqueous solutions of ICG, IHANPT, and PBS were added into $1.5 \mathrm{~mL}$ Eppendorf tubes containing $1 \mu \mathrm{M}$ of $2^{\prime}, 7^{\prime}$ dichlorofluorescin-diacetate in PBS with 2\% DMSO and irradiated with an $808 \mathrm{~nm}$ continuous laser at a power of $0.3 \mathrm{~W} / \mathrm{cm}^{2}$ for $10 \mathrm{~min}$. The entire surface of the samples was adjusted to confirm that they were covered by the laser spot. The fluorescent intensity that is proportional to the amount of $1 \mathrm{O}_{2}$ was detected with the fluorescence spectrometer with 488 $\mathrm{nm}$ excitation and $525 \mathrm{~nm}$ emission. Temperature of all samples were controlled by incubation phantoms in water bath. The total light dose was $90 \mathrm{~J} / \mathrm{cm}^{2}$ for in vitro photodynamic therapy evaluation.

A commercial ${ }^{1} \mathrm{O}_{2}$ kit, singlet oxygen sensor green (SOSG), was employed to study IHANPT-enhanced generation of ${ }^{1} \mathrm{O}_{2}$ in the cells. The fluorescence of SOSG (ex/em: $490 / 525 \mathrm{~nm}$ ) is quenched in its intact form and produces strong fluorescence after ${ }^{1} \mathrm{O}_{2}$ oxidation. Briefly, SCC7 cells were seeded into an eight-well chamber and incubated overnight. The next day, $2 \mu \mathrm{L}$ of SOSG working solution was added $30 \mathrm{~min}$ ahead of the addition of IHANPT. Then, an $808 \mathrm{~nm}$ continuous laser was applied on cells at a power of $0.3 \mathrm{~W} / \mathrm{cm}^{2}$ for $2 \mathrm{~min}$. After removing the medium and incubated with fresh medium, the cells were stained with EthD-III at $37{ }^{\circ} \mathrm{C}$ and imaged with a confocal microscope (Leica, Germany).

\section{Cytotoxicity}

The SCC7 cells were cultured in DMEM/high glucose medium containing 10\% FBS and 1\% antibiotic solution at $37{ }^{\circ} \mathrm{C}$ and $5 \% \mathrm{CO}_{2}$. SCC7 cells were seeded in a 96-well plate at 5000 cells per well, and cultured for overnight at $37^{\circ} \mathrm{C}$ in a $5 \% \mathrm{CO}_{2}$ incubator. The next day, cells were washed with PBS and incubated with IHANPT solutions at a series of concentrations (containing 0-500 $\mu \mathrm{g} / \mathrm{mL}$ IHANPT, 0-72 $\mu \mathrm{g} / \mathrm{mL}$ SWCNTs, 0-26 $\mu \mathrm{g} / \mathrm{mL}$ free ICG, $100 \mu \mathrm{L} /$ 
well) for $24 \mathrm{~h}$ under the same conditions. After washing with PBS, the experimental cell medium was replaced with a fresh DMEM culture medium $(100 \mu \mathrm{L})$ and exposed to the 808 $\mathrm{nm}$ laser for $10 \mathrm{~min}\left(0.3 \mathrm{~W} / \mathrm{cm}^{2}\right)$. Subsequently, cells were incubated at $37{ }^{\circ} \mathrm{C}$ in a $5 \% \mathrm{CO}_{2}$ incubator for $12 \mathrm{~h}$. The control groups were incubated under the same conditions without irradiation. Cell viability was evaluated by CCK-8 assay kit. Optical density (OD) was measured at $450 \mathrm{~nm}$ and recorded with a microplate reader. To compare the phototoxicity effect of different nanomaterials, cells were exposed to HANP, free ICG, HANPT, or IHANPT for $24 \mathrm{~h}$. The groups were illuminated with an $808 \mathrm{~nm}$ laser $\left(0.3 \mathrm{~W} / \mathrm{cm}^{2}\right)$ and incubated for an additional $12 \mathrm{~h}$. The control groups were grown in darkness at $37{ }^{\circ} \mathrm{C}$ under $5 \% \mathrm{CO}_{2}$. Cell viabilities were then measured with the CCK-8 assay.

\section{Calcein AM/PI Staining}

The SCC7 cells were seeded in a six-well plate with a density of $1 \times 10^{5}$ cells/well and grown to $80 \%-90 \%$ confluence. The SCC7 cells were incubated with HANP, free ICG, HANPT, and IHANPT for $24 \mathrm{~h}$, respectively. After washing three times with PBS to remove the free samples, cells were immersed in a fresh culture medium and illuminated using a laser beam $\left(808 \mathrm{~nm}, 0.3 \mathrm{~W} / \mathrm{cm}^{2}\right)$ for $10 \mathrm{~min}$. Specifically, the ICG group were illuminated with a laser $\left(808 \mathrm{~nm}, 0.3 \mathrm{~W} / \mathrm{cm}^{2}\right)$ for $10 \mathrm{~min}$ and the temperature was monitored and kept below $55^{\circ} \mathrm{C}$. For PDT treatment of cells, SCC7 cells with IHANPT were laser-irradiated to maintain a constant temperature $\left(37^{\circ} \mathrm{C}\right)$ and avoid photothermal effects. The PTT effect was conducted via continuous laser irradiation $\left(808 \mathrm{~nm}, 0.3 \mathrm{~W} / \mathrm{cm}^{2}\right)$ of the cells for $10 \mathrm{~min}$. For PDT and PTT combined treatment, SCC7 cells were irradiated with a laser and the temperature was kept below $55^{\circ} \mathrm{C}$. The laser spot was adjusted to fully cover the area of each well, and the total light dose was $90 \mathrm{~J} / \mathrm{cm}^{2}$. After illumination, cells were incubated at $37{ }^{\circ} \mathrm{C}$ with $5 \% \mathrm{CO}_{2}$ for $4 \mathrm{~h}$. Control groups in darkness were incubated in a fresh DMEM medium. After removing the medium, calcein AM $(4 \mu \mathrm{mol} / \mathrm{L})$ and PI solutions $(4 \mu \mathrm{mol} / \mathrm{L})$ in PBS were added to SCC7 cells and incubated for $30 \mathrm{~min}$ at $37{ }^{\circ} \mathrm{C}$ with $5 \% \mathrm{CO}_{2}$. Finally, the cells were washed for three times and imaged with a fluorescence microscope.

\section{In Vivo Imaging of SCC7 Tumor Xenografts in Nude Mice}

All animal experiments were conducted under protocols approved by the Animal Care and Use Committee (CC/ACUCC) of Xiamen University. A suspension of $5 \times 10^{6}$ of SCC7 cells in PBS $(80 \mu \mathrm{L})$ was injected subcutaneously into athymic (nu/nu) mice (7 weeks old, female, $16-18 \mathrm{~g}$ ). When tumors reached a volume of $60-80 \mathrm{~mm}^{3}, 100 \mu \mathrm{L}$ of HANP, free ICG, HANPT, and IHANPT (dose: $1 \mathrm{mg} / \mathrm{kg}$ ICG, $2.72 \mathrm{mg} / \mathrm{kg}$ SWCNTs) was injected via the tail vein, respectively. Real-time PA signals in the tumor sites were recorded with Endra Nexus128 (Ann Arbor, MI) at time points of 0, 1, 4, 6, 12, 24, and $48 \mathrm{~h}$. Mice in different groups were sacrificed $24 \mathrm{~h}$ after injection. Tumors and normal tissues, such as hearts, livers, kidneys, lungs, muscles, and spleens, were collected and imaged and then analyzed using Endra Nexus128.

\section{In Vivo Photothermal Therapy of IHANPT}

SCC-7 tumor models were established by subcutaneous injection of $5 \times 10^{6}$ cells into the right leg of female athymic nude mice ( 7 weeks old, female, 16-18 g). Tumor-bearing mice were randomly divided into eight groups ( $n=5$ /group): (a) PBS without laser, (b) PBS with 
laser, (c) free ICG without laser, (d) free ICG with laser, (e) HANPT without laser, (f) HANPT with laser, (g) IHANPT without laser, (h) IHANPT with interval laser, and (i) IHANPT with laser. Tumor growth was monitored by caliper measurements three times a week after the tumors were palpable. When the tumor size reached an average size of 60-80 $\mathrm{mm}^{3}$, the tumor-bearing mice were injected with $100 \mu \mathrm{L}$ of PBS, HANP, free ICG, HANPT, or IHANPT (dose: $1 \mathrm{mg} / \mathrm{kg}$ ICG, $2.72 \mathrm{mg} / \mathrm{kg}$ SWCNTs) through the tail vein. Twenty-four hours $(24 \mathrm{~h})$ post-injection, the tumors were illuminated with the $808 \mathrm{~nm}$ laser beam at a power density of $0.8 \mathrm{~W} / \mathrm{cm}^{2}$ for $10 \mathrm{~min}$. The total light dose was $240 \mathrm{~J} / \mathrm{cm}^{2}$ for tumor phototherapy. Meanwhile, thermal images in tumors were taken using a FLIR A5 camera and quantified by BM-IR software. Tumor volumes were determined using the formula

$$
V=a \times \frac{b^{2}}{2}
$$

where $a$ and $b$ are the length and width of each tumor, respectively (given in millimeters). Compared to the original tumor volume, the volume of tumors was evaluated by normalizing the measured values. Relative tumor volumes of all groups were calculated for 14 days after the treatment. During the injection and photothermal therapy processes, the mice were anesthetized with $2.5 \%$ isoflurane in oxygen that was delivered at a flow rate of $1.5 \mathrm{~L} / \mathrm{min}$.

\section{Histology Staining}

Two weeks after the treatments, animals were sacrificed and tumors and major organs were collected for analysis. In the IHANPT-treated group, the tumors were collected on Day 3 after laser irradiation. The $8 \mu \mathrm{m}$ tissue sections were stained with hematoxylin and eosin (H\&E), using a standard protocol. All tissue sections were examined under a Leica confocal microscope.

\section{Statistical Analysis}

Comparisons among groups were analyzed via independent-samples one-factor ANOVA testing, using SPASS 17.0 software. All statistical data were obtained using a two-tailed Student's $t$-test and homogeneity of variance tests ( $p$-values of $<0.05$ were considered to be significant).

\section{RESULTS AND DISCUSSION \\ Preparation and Characterization of IHANPT}

The HANPs were initially synthesized as previously reported ${ }^{27}$ and covalently labeled with ICG to generate ${ }^{1} \mathrm{O}_{2}$ and create local hyperthermia for PDT and PTT applications. After conjugation, the SWCNTs with high photothermal conversion efficiency were encapsulated to further improve phototherapy efficiency via a high-pressure homogenizer. The final product, ICG-conjugated HANP-fabricated SWCNT, was referenced as IHANPT (Figure 1). To optimize the ratio between SWCNTs and IHANP, different amounts of SWCNTs (10\%, $20 \%$, and $40 \%(\mathrm{w} / \mathrm{w})$ ) were loaded into IHANP, and the loading efficiency was calculated and presented in Table 1. We found that the highest loading efficiency was estimated to be $70.1 \%$ when the SWCNT:IHANP ratio was 1:4 (w/w), and the proportion of SWCNT and 
IHANP was chosen throughout our study. However, precise quantification of the HANP cargo is difficult, because of the fact that the exact number of HA subunits in HANP, so far, is unclear. Therefore, for future clinical translation, more cooperation between physicists and chemists are required to clarify the composition of HANP. Successful construction of this complex was confirmed by ultraviolet-visible-near-infrared (UV-vis-NIR) spectra (see Figure 2a). IHANPT has a peak at $800 \mathrm{~nm}$, which suggests successful conjugation and encapsulation of ICG and SWCNT. Since free ICG only has a strong absorbance at $780 \mathrm{~nm}$, we believe that the red shift in IHANPT is attributed to the close interactions between ICG and SWCNT. Although SWCNTs were very prone to aggregate without surface modifications (Figure S1 in the Supporting Information), there was excellent solubility and stability of IHANPT in aqueous solution (water, PBS, cell medium, and cell medium containing 10\% FBS), which suggests that SWCNTs are successfully loaded into the interior of the IHANP (see Figure 2b). Neither IHANPT sample showed UV-vis absorbance spectra changes, even after 2 weeks of incubation in aqueous solution at room temperature (see Figure 2 and Figure S1). Given the strong optical absorbance of ICG and SWCNT, photoacoustics signal from IHANPT were measured and quantified (see Figures $2 \mathrm{c}$ and $2 \mathrm{~d}$ ). Overall, we demonstrated good stability and strong PA signals of IHANPT. The successful encapsulation of SWCNT into IHANP made it possible to conduct in vivo applications of IHANPT as a theranostic agent.

\section{Cell Targetability of IHANP}

Before moving forward, tumor cells targetability of IHANP was investigated on CD44 positive and negative cell lines by cell fluorescent staining. It is known that CD44 is a frequently overexpressed tumoral cells and can bind with HA. As shown in Figure S2 in the Supporting Information, strong fluorescence signals were observed in CD44 positive SCC7 cells, but very little fluorescent signal was seen in CD44 negative NIH3T3 cells. Although some IHANPs were able to be internalized nonspecifically by NIH-3T3 cells, the amount was small and only weak fluorescent signals can be observed, compared to that of SCC7 cells. To confirm the binding specificity of IHANP to CD44, a competitive binding study was performed. CD44 expressed on SCC7 cells was saturated by first incubating them with an excess amount of free HANP and then treating them with IHANP (Figure S2). After $3 \mathrm{~h}$ of incubation, only a weak fluorescent signal can be observed, compared to that observed for SCC7 cells without CD44 blocking. This implies that IHANP has specific and strong CD44 binding ability and can target the tumor cells by active CD44-receptor-mediated targeting, as well as via an EPR effect. This dual-targeting property makes IHANP an ideal candidate as an theranostics agent.

\section{Evaluation of Hyperthermia and Generation of ${ }^{1} \mathrm{O}_{2}$ via IHANPT In Vitro}

To evaluate the therapeutic effect, we evaluated the ability of IHANPT in inducing the hyperthermia and generating $1 \mathrm{O}_{2}$ in tumor cells in vitro. The ICG photothermal property was first verified using different power laser irradiations. A significant temperature increase was detected, suggesting the potential of using ICG for photothermal therapy (Figure S3 in the Supporting Information). Next, we tested the phantom photothermal properties. Different samples (IHANPT, HANPT, ICG, and HANP) were exposed to an $808 \mathrm{~nm}$ laser at $0.3 \mathrm{~W} /$ $\mathrm{cm}^{2}$. Temperature changes were monitored using an infrared thermal camera. All sample 
concentrations were adjusted to confirm that they contained the same amount of ICG (10 $\mu \mathrm{g} / \mathrm{mL}$ ) or SWCNT ( $35 \mu \mathrm{g} / \mathrm{mL}$ ). As expected, the temperature of IHANPT increased from $25^{\circ} \mathrm{C}$ to $55^{\circ} \mathrm{C}$ within $\sim 4$ min, which was much faster and higher than HANPT or free ICG alone (see Figure 3 and Figure S4 in the Supporting Information). Therefore, the combination of SWCNT and ICG did not affect the photothermal property of ICG, and encapsulation of the SWCNTs did, indeed, improve the photothermal conversion efficiency of IHANPT. We also found that there was no obvious temperature change in the free HANP group with laser illumination.

In addition, the PDT property of IHANPT was evaluated. Different amounts of ICG were prepared and irradiated by a NIR laser $\left(808 \mathrm{~nm}, 0.3 \mathrm{~W} / \mathrm{cm}^{2}\right)$. Interestingly, we found that the $1 \mathrm{O}_{2}$ concentration decreased as a function of ICG concentration (see Figure S5 in the Supporting Information). It is known that ICG is not stable at high temperatures; ${ }^{37,38}$ therefore, we explored the effect of temperature on $1 \mathrm{O}_{2}$ generation. To avoid the temperature effect on ${ }^{1} \mathrm{O}_{2}$ kit, the fluorescent changes of DCF at different temperatures were evaluated. As expected, no significant fluorescent changes were observed (see Figure S6 in the Supporting Information), implying that DCF is able to evaluate the ${ }^{1} \mathrm{O}_{2}$ generation of ICG in vitro. As shown in Figure 3c, similar amounts of ${ }^{1} \mathrm{O}_{2}$ were generated when the temperature was controlled to be $<55{ }^{\circ} \mathrm{C}$; however, ${ }^{1} \mathrm{O}_{2}$ significantly decreased when the temperature exceeded $65{ }^{\circ} \mathrm{C}$ (see Figure $\mathrm{S} 7$ in the Supporting Information). The ${ }^{1} \mathrm{O}_{2}$ generation ability of IHANPT in cells was confirmed by Singlet Oxygen Sensor Green (SOSG), as shown in Figure S8 in the Supporting Information. We concluded that a temperature of $<55{ }^{\circ} \mathrm{C}$ in the tumor is optimal, because it can simultaneously protect ICG and ablate cancer cells. Similar amounts of ${ }^{1} \mathrm{O}_{2}$ were generated by IHANPT versus free ICG when the temperature was $<55^{\circ} \mathrm{C}$. Our study suggested that the encapsulation of SWCNT into IHANP did not affect the ${ }^{1} \mathrm{O}_{2}$ generation of ICG (Figure 3d). Overall, nanoparticles containing ICG and SWCNTs (IHANPT) have an enhanced photothermal conversion efficiency compared with ICG or SWCNT alone. The dual hyperthermal and $1 \mathrm{O}_{2}$ effects of IHANPT are optimal when the core temperature is controlled at $<55^{\circ} \mathrm{C}$. This results in sufficient levels of tumor cells ablation and ${ }^{1} \mathrm{O}_{2}$ production from ICG.

\section{Synergistic Effect of Phototherapy Using IHANPT in Tumor Cells In Vitro}

Given the excellent thermal and ${ }^{1} \mathrm{O}_{2}$ generation abilities of IHANPT, the therapeutic effect of IHANPT was further evaluated in vitro by monitoring the viability of SCC7 cells with or without laser irradiation. The effect of IHANPT was examined quantitatively by MTT assay on SCC7 cells. As shown in Figure 4a, 91.4\% $\pm 3.58 \%$ of cells were dead after treatment with $500 \mu \mathrm{g} / \mathrm{mL}$ IHANPT ( $\sim 70 \mu \mathrm{g} / \mathrm{mL}$ of SWCNTs and $16 \mu \mathrm{g} / \mathrm{mL}$ of ICG) and laser irradiation at $808 \mathrm{~nm}$ and $0.3 \mathrm{~W} / \mathrm{cm}^{2}$. However, the effect of the treatment decreased as the IHANPT concentration and laser irradiation was reduced. The $\mathrm{IC}_{50}$ of IHANPT was $\sim 120$ $\mu \mathrm{g} / \mathrm{mL}$ to SCC7 cells. Moreover, without laser irradiation, there was no obvious cytotoxicity after IHANPT treatment.

To verify advantages of IHANPT over free ICG or SWCNT, the effect of tumor cell ablation was compared among different materials. As shown in Figure 4b, almost all cells were dead after in-IHANPT treatment, while more than $50 \%$ of cells survived in the ICG or HANPT- 
treated group. The HANP itself did not show toxicity to SCC7 cells without or with laser irradiation. The combined therapeutic effects of IHANPT also are shown in Figure 4b. The laser was temporarily illuminated on the IHANPT-incubated cells to ensure that the temperature did not exceed $37^{\circ} \mathrm{C}$, which was considered to be most effective temperature for PDT. Similar to PTT alone, only $45.4 \% \pm 6.07 \%$ of cells were dead in the IHANPT with periodic laser irradiation. This was much weaker than that of IHANPT with the laser-treated group. Cytotoxicity was also confirmed by Calcein-AM and PI staining (Figure 4c). The effect of induction in tumor cell death in vitro was much stronger in IHANPT-treated cells than that of ICG or SWCNT alone, showing its potential as a phototherapy agent.

\section{Photoacoustic (PA) Imaging of Tumor Targeted Delivery of IHANPT, Following Systemic Administration}

PA imaging is a promising approach for future clinical translation in cancer patients, because it has increased imaging depth and improved resolution for detection of tumors in deep tissue. It has the ability to analyze blood vessel distribution and nanomaterial accumulation in tumors. In our study, the strong absorbance of IHANPT allowed us to analyze the accumulation of IHANPT in tumors by PA imaging. To achieve an efficient tumor ablation effect, phototherapy proceeding time window was determined when IHANPT peaked in the tumor area. As shown in Figure 5, the in vivo biodistribution and tumor selectivity of IHANPT were investigated in a subcutaneous (sc) SCC7 tumor model.

The PA contrast of the IHANPT-treated group was increased over time $(1.14 \pm 0.29,2.07$ $\pm 0.33,2.89 \pm 0.17$, and $5.19 \pm 0.3$ at $1,6,12,24 \mathrm{~h} \mathrm{PI})$, compared to the level of the PA signal preinjection. The PA contrast decreased due to the clearance of IHANPT in vivo at 48 $\mathrm{h}$ after injection. In the control group, when free ICG was injected, there was no clear PA signal, because free ICG could not enrich in the tumor area, as confirmed by optical imaging (see Figure S9 in the Supporting Information). This demonstrated the importance of targeted delivery using IHANPT for tumor phototherapy. Although HANPT had some tumor uptake, the PA signal was as high as IHANPT, because of its weaker absorbance, compared with IHANPT. No PA imaging signal was not detected in HANP-injected mice, since HANP alone did not have a PA effect. The excellent tumor targeting of IHANPT was also verified ex vivo. As shown in Figure S10 in the Supporting Information, only the liver showed increased PA signals, with the exception of the tumor. No obvious PA signals were found in major normal organs in the SCC7 tumor-bearing mice treated with IHANPT. A high level of liver uptake might be due to land nonspecific uptake by Kupffer cells in the liver. The liver from the IHANPT-treated group demonstrated high PA signal versus the HANPT group. It was not surprising that IHANPT had a higher PA signal than HANPT, even though they are at the same concentration, since IHANPT demonstrated a higher PA effect than that HANPT originally. Considering results obtained from both the in vivo and ex vivo analyses, we have demonstrated that IHANPT is an excellent tumor targeting and phototherapy agent. Identification of a peak accumulation of the nanoparticle in tumors at $24 \mathrm{~h}$ after injection provides us an optimized phototherapy time point for future studies. 


\section{Synergistic Antitumor Efficacy of IHANPT In Vivo}

Although IHANPT had excellent photothermal conversion efficiency and generated very high temperatures with a short laser exposure in vitro, the applications of thermal therapy in human patients requires mild temperatures, to avoid serious skin damage. Meanwhile, to ensure that the tumor temperature reaches a threshold to induce irreversible tumor ablation and PDT effect, a very low laser power density $\left(808 \mathrm{~nm}, 0.8 \mathrm{~W} / \mathrm{cm}^{2}\right)$ was selected. The antitumor effects of synergistic PTT and PDT treatment of IHANPT were evaluated in nude mice bearing SCC7 tumors after intravenous injection of IHANPT (containing $10 \mu \mathrm{g}$ of SWCNTs and $5 \mu \mathrm{g}$ of ICG in $100 \mu \mathrm{L}$ ). The tumor region was then irradiated with a NIR laser $\left(808 \mathrm{~nm}, 0.8 \mathrm{~W} / \mathrm{cm}^{2}, 10 \mathrm{~min}\right)$ at $24 \mathrm{~h}$ after the injection. The photothermal effect of IHANPT was monitored through an infrared thermal imaging camera (see Figures $6 \mathrm{a}$ and $6 \mathrm{~b})$. The tumor surface temperature of IHANPT-treated mice reached $55.4 \pm 1.8^{\circ} \mathrm{C}$, following $10 \mathrm{~min}$ of irradiation. This is apparently higher than that of HANPT (Figure 6b). Compared to normal mouse body temperature, a moderate temperature increase $(9.7$ $\pm 0.49^{\circ} \mathrm{C}$ ) in the tumor was observed in free ICG-injected mice, because of the insufficient tumor accumulation, while tumors in mice injected with HANP only increased by 7.3 $\pm 0.51{ }^{\circ} \mathrm{C}$. It is noticeable that HANP does not demonstrate a PTT effect in vitro, and this increased temperature may be attributed to the continuous laser illumination on skin. To achieve PDT effect alone, tumors were irradiated by repeating laser irradiation at $5 \mathrm{~min}$ intervals, which can significantly reduce the local laser irradiation caused temperature increase. The tumor growth rate was monitored and recorded continuously for 2 weeks (Figure 6c). The tumor grew relatively fast in HANP and free ICG-treated groups, indicating that simple thermal laser therapy is insufficient to inhibit tumor growth. The tumor growth was slightly inhibited by IHANPT with interrupted laser irradiation. However, the tumors relapsed 3 days after treatment. This indicated that the PDT alone produced by IHANPT could only partially suppressed tumor growth. HANPT, coupled with laser irradiation, hindered tumor growth to a certain extent, but it eventually recurred. This revealed the low therapeutic efficacy of PTT alone with low laser power. Effective tumor ablation occurred when mice were injected with IHANPT in combination with laser exposure. The tumors were mostly ablated as soon as 2 days after treatment; no recurrence was found. We did not observe obvious body weight changes during the experiment (Figure 6d). To precisely observe the tumor growth after different treatments, mice were examined by a $9.4 \mathrm{~T}$ MRI (Figure 6e). The exact tumor sizes after treatment were measured in MR images and shown in Figure 6f. The MRI results showed that tumors treated with HANPT and IHANPT at periodic laser irradiation were partially suppressed but had regrowth five days posttreatment. In contrast, the IHANPT-treated tumor started shrinking after the treatment and did not have recurrent tumors. The tumor growth of the control mice without laser irradiation was not affected, as seen in the MRI data (see Figure S11 in the Supporting Information).

To confirm the effect of IHANPT-mediated phototherapy, tumor tissues and normal organs from the mice treated with HANP, free ICG, HANPT, and IHANPT were harvested for further histological analysis. The H\&E staining of tumor sections collected from the treated mice showed necrotic tumor areas in the tumors treated with IHANPT and periodic irradiation. Extensive tumor necrosis was observed in the IHANPT-treated group with 
continuous NIR laser irradiation (PDT/PTT). As shown in Figure 7, only slight tumor necrosis could be seen in the HANP and free-ICG-treated groups. No obvious destruction in the tumor was found in either control groups or IHANPT groups without laser irradiation. The major normal organs from SCC7 tumor-bearing nude mice of each group, including the heart, liver, spleen, lung, and kidney, were analyzed. There was no noticeable tissue damage found in H\&E-stained tissue sections. These data demonstrated that IHANPT, in combination with laser irradiation, did not have toxic side effects in normal tissues of nude mice. Collectively, our results verified that IHANPT are promising PA image-guided phototherapy agents with improved therapeutic efficacy in cancer treatment.

\section{CONCLUSIONS}

In summary, we have developed a promising theranostic nanocomplex of ICG-HANP/ SWCNTs (IHANPT) for PA-guided photothermal and photodynamic cancer therapy. This multifunctional theranostic nanoparticle can target CD44, which is highly expressed in aggressive tumor cells. Phototherapy efficacy for tumor ablation is mediated by a dual PTT and PDT effect of ICG that is conjugated on the nanoparticles. The PTT effect is further enhanced by embedded SWCNTs. The combination of ICG and SWCNT generates a strong PA signal for sensitive PA imaging of the targeted delivery of this theranostic nanoparticle with tumor responses to the therapy. Our IHANPTs have excellent biocompatibility and tumor targeting due to the EPR effect and CD44 receptor-mediated endocytosis. While ICG is not stable at high temperatures, we determined that ICG is a promising PDT agent for combined phototherapy below $55{ }^{\circ} \mathrm{C}$. The in vitro and in vivo studies showed that the IHANPT induced cancer cell death effectively under a low NIR laser exposure via combined PTT and PDT mechanism. Overall, our results demonstrated that IHANPT is a novel class of the multifunctional and multimodality theranostic nanoparticle that can be used for PAguided and simultaneous PTT- and PDT-mediated cancer therapy. Relative to other phototherapy agents, IHANPT enhanced tumor targeting via the EPR effect and active CD44 targeting. This results in an effective delivery of phototherapeutic agent in tumors. IHANPT can ablate tumors and provide imaging data with low side effects off-target. This technology extends the ICG-based phototherapy applications and has great potential for future clinical translation.

\section{Supplementary Material}

Refer to Web version on PubMed Central for supplementary material.

\section{Acknowledgments}

This work was supported by National Science Foundation of China (NSFC) (Nos. 51373144 and 81201129), National High Technology Research and Development Program of China (863 Program) (No. 2014AA020708), and Fundamental Research Funds for the Central Universities (No. 20720150064).

\section{References}

1. Huang P, Lin J, Li W, Rong P, Wang Z, Wang S, Wang X, Sun X, Aronova M, Niu G, Leapman RD, Nie Z, Chen X. Biodegradable Gold Nanovesicles with an Ultrastrong Plasmonic Coupling Effect for Photoacoustic Imaging and Photothermal Therapy. Angew Chem. 2013; 125:14208-14214. 
2. Menon JU, Jadeja P, Tambe P, Vu K, Yuan B, Nguyen KT. Nanomaterials for Photo-Based Diagnostic and Therapeutic Applications. Theranostics. 2013; 3:152-166. [PubMed: 23471164]

3. Rai P, Mallidi S, Zheng X, Rahmanzadeh R, Mir Y, Elrington S, Khurshid A, Hasan T. Development and Applications of Photo-Triggered Theranostic Agents. Adv Drug Delivery Rev. 2010; 62:10941124.

4. Zhang Z, Wang J, Chen C. Near Infrared Light Mediated Nanoplatforms for Cancer Thermo Chemotherapy and Optical Imaging. Adv Mater. 2013; 25:3869-3880. [PubMed: 24048973]

5. Zha Z, Wang J, Qu E, Zhang S, Jin Y, Wang S, Dai Z. Polypyrrole Hollow Microspheres as Echogenic Photothermal Agent for Ultrasound Imaging Guided Tumor Ablation. Sci Rep. 2013; 3:2360. [PubMed: 23912977]

6. Tian Q, Jiang F, Zou R, Liu Q, Chen Z, Zhu M, Yang S, Wang J, Wang J, Hu J. Hydrophilic Cu9 $\mathrm{S}_{5}$ Nanocrystals: A Photothermal Agent with a 25.7\% Heat Conversion Efficiency for Photothermal Ablation of Cancer Cells In Vivo. ACS Nano. 2011; 5:9761-9771. [PubMed: 22059851]

7. Tian Q, Tang M, Sun Y, Zou R, Chen Z, Zhu M, Yang S, Wang J, Wang J, Hu J. Hydrophilic Flower Like CuS Superstructures as an Efficient $980 \mathrm{~nm}$ Laser Driven Photothermal Agent for Ablation of Cancer Cells. Adv Mater. 2011; 23:3542-3547. [PubMed: 21735487]

8. Liu X, Wang X, Zhou B, Law WC, Cartwright AN, Swihart MT. Size-Controlled Synthesis of $\mathrm{Cu}_{2-} X^{\mathrm{E}}(\mathrm{E}=\mathrm{S}, \mathrm{Se})$ Nanocrystals with Strong Tunable Near-Infrared Localized Surface Plasmon Resonance and High Conductivity in Thin Films. Adv Funct Mater. 2013; 23:1256-1264.

9. Shen H, Zhang L, Liu M, Zhang Z. Biomedical Applications of Graphene. Theranostics. 2012; 2:283. [PubMed: 22448195]

10. Zha Z, Deng Z, Li Y, Li C, Wang J, Wang S, Qu E, Dai Z. Biocompatible Polypyrrole Nanoparticles as a Novel Organic Photoacoustic Contrast Agent for Deep Tissue Imaging. Nanoscale. 2013; 5:4462-4467. [PubMed: 23584573]

11. Zhang M, Murakami T, Ajima K, Tsuchida K, Sandanayaka AS, Ito O, Iijima S, Yudasaka M. Fabrication of ZnPc/Protein Nanohorns for Double Photodynamic and Hyperthermic Cancer Phototherapy. Proc Natl Acad Sci U S A. 2008; 105:14773-14778. [PubMed: 18815374]

12. Nurunnabi M, Khatun Z, Reeck GR, Lee DY, Lee YK. Photoluminescent Graphene Nanoparticles for Cancer Phototherapy and Imaging. ACS Appl Mater Interfaces. 2014; 6:12413-12421. [PubMed: 25054687]

13. Peng J, Zhao L, Zhu X, Sun Y, Feng W, Gao Y, Wang L, Li F. Hollow Silica Nanoparticles Loaded with Hydrophobic Phthalocyanine for Near-Infrared Photodynamic and Photothermal Combination Therapy. Biomaterials. 2013; 34:7905-7912. [PubMed: 23891514]

14. Cheng L, Wang C, Feng L, Yang K, Liu Z. Functional Nanomaterials for Phototherapies of Cancer. Chem Rev. 2014; 114:10869-10939. [PubMed: 25260098]

15. Smith AM, Mancini MC, Nie S. Bioimaging: Second Window for In Vivo Imaging. Nat Nanotechnol. 2009; 4:710-711. [PubMed: 19898521]

16. Zheng C, Zheng M, Gong P, Jia D, Zhang P, Shi B, Sheng Z, Ma Y, Cai L. Indocyanine GreenLoaded Biodegradable Tumor Targeting Nanoprobes for In Vitro and In Vivo Imaging. Biomaterials. 2012; 33:5603-5609. [PubMed: 22575835]

17. Zhen Z, Tang W, Guo C, Chen H, Lin X, Liu G, Fei B, Chen X, Xu B, Xie J. Ferritin Nanocages to Encapsulate and Deliver Photosensitizers for Efficient Photodynamic Therapy against Cancer. ACS Nano. 2013; 7:6988-6996. [PubMed: 23829542]

18. Huang P, Rong P, Jin A, Yan X, Zhang MG, Lin J, Hu H, Wang Z, Yue X, Li W, Niu G, Zeng W, Wang W, Zhou K, Chen X. Dye-Loaded Ferritin Nanocages for Multimodal Imaging and Photothermal Therapy. Adv Mater. 2014; 26:6401-6408. [PubMed: 25123089]

19. Zheng M, Yue C, Ma Y, Gong P, Zhao P, Zheng C, Sheng Z, Zhang P, Wang Z, Cai L. Single-Step Assembly of DOX/ICG Loaded Lipid-Polymer Nanoparticles for Highly Effective ChemoPhotothermal Combination Therapy. ACS Nano. 2013; 7:2056-2067. [PubMed: 23413798]

20. Sheng Z, Hu D, Zheng M, Zhao P, Liu H, Gao D, Gong P, Gao G, Zhang P, Ma Y, Cai L. Smart Human Serum Albumin-Indocyanine Green Nanoparticles Generated by Programmed Assembly for Dual-Modal Imaging-Guided Cancer Synergistic Phototherapy. ACS Nano. 2014; 8:1231012322. [PubMed: 25454579] 
21. Kuo W-S, Chang Y-T, Cho K-C, Chiu K-C, Lien C-H, Yeh C-S, Chen S-J. Gold Nanomaterials Conjugated with Indocyanine Green for Dual-Modality Photodynamic and Photothermal Therapy. Biomaterials. 2012; 33:3270-3278. [PubMed: 22289264]

22. Maeda H. Toward a Full Understanding of the Epr Effect in Primary and Metastatic Tumors as Well as Issues Related to Its Heterogeneity. Adv Drug Delivery Rev. 2015; 91:3-6.

23. Maeda H, Nakamura H, Fang J. The Epr Effect for Macromolecular Drug Delivery to Solid Tumors: Improvement of Tumor Uptake, Lowering of Systemic Toxicity, and Distinct Tumor Imaging In Vivo. Adv Drug Delivery Rev. 2013; 65:71-79.

24. Gao S, Zhang L, Wang G, Yang K, Chen M, Tian R, Ma Q, Zhu L. Hybrid Graphene/Au Activatable Theranostic Agent for Multimodalities Imaging Guided Enhanced Photothermal Therapy. Biomaterials. 2016; 79:36-45. [PubMed: 26691399]

25. Zhang L, Rong P, Chen M, Gao S, Zhu L. A Novel Single Walled Carbon Nanotube (SWCNT) Functionalization Agent Facilitating In Vivo Combined Chemo/Thermo Therapy. Nanoscale. 2015; 7:16204-16213. [PubMed: 26234690]

26. Yang K, Zhu L, Nie LM, Sun XL, Cheng L, Wu CX, Niu G, Chen XY, Liu Z. Visualization of Protease Activity in vivo Using an Activatable Photo-Acoustic Imaging Probe Based on $\mathrm{CuS}$ Nanoparticles. Theranostics. 2014; 4:134-141. [PubMed: 24465271]

27. Zhang L, Gao S, Zhang F, Yang K, Ma Q, Zhu L. Activatable Hyaluronic Acid Nanoparticle as a Theranostic Agent for Optical/Photoacoustic Image-Guided Photothermal Therapy. ACS Nano. 2014; 8:12250-12258. [PubMed: 25402600]

28. Lapčík L, Lapcik L, De Smedt S, Demeester J, Chabrecek P. Hyaluronan: Preparation, Structure, Properties, and Applications. Chem Rev. 1998; 98:2663-2684. [PubMed: 11848975]

29. Skandalis SS, Gialeli C, Theocharis AD, Karamanos NK. Advances and Advantages of Nanomedicine in the Pharmacological Targeting of Hyaluronan-CD44 Interactions and Signaling in Cancer. Adv Cancer Res. 2014; 123:277-317. [PubMed: 25081534]

30. Swierczewska M, Choi KY, Mertz EL, Huang X, Zhang F, Zhu L, Yoon HY, Park JH, Bhirde A, Lee S, Chen X. A Facile, One-Step Nanocarbon Functionalization for Biomedical Applications. Nano Lett. 2012; 12:3613-3620. [PubMed: 22694219]

31. De la Zerda A, Zavaleta C, Keren S, Vaithilingam S, Bodapati S, Liu Z, Levi J, Smith BR, Ma TJ, Oralkan O, Cheng Z, Chen X, Dai H, Khuri-Yakub BT, Gambhir SS. Carbon Nanotubes as Photoacoustic Molecular Imaging Agents in Living Mice. Nat Nanotechnol. 2008; 3:557-562. [PubMed: 18772918]

32. De la Zerda A, Bodapati S, Teed R, May SY, Tabakman SM, Liu Z, Khuri-Yakub BT, Chen X, Dai H, Gambhir SS. Family of Enhanced Photoacoustic Imaging Agents for High-Sensitivity and Multiplexing Studies in Living Mice. ACS Nano. 2012; 6:4694-4701. [PubMed: 22607191]

33. Wang J, Zhang L, Chen M, Gao S, Zhu L. Activatable Ferritin Nanocomplex for Real-Time Monitoring of Caspase-3 Activation During Photodynamic Therapy. ACS Appl Mater Interfaces. 2015; 7:23248-23256. [PubMed: 26388178]

34. Zhou FF, Wu SN, Wu BY, Chen WR, Xing D. Mitochondria-Targeting Single-Walled Carbon Nanotubes for Cancer Photothermal Therapy. Small. 2011; 7:2727-2735. [PubMed: 21861293]

35. Zhou F, Wu S, Song S, Chen WR, Resasco DE, Xing D. Antitumor Immunologically Modified Carbon Nanotubes for Photothermal Therapy. Biomaterials. 2012; 33:3235-3242. [PubMed: 22296829]

36. Harada H, Takahashi M. Cd44-Dependent Intracellular and Extracellular Catabolism of Hyaluronic Acid by Hyaluronidase-1 and -2. J Biol Chem. 2007; 282:5597-5607. [PubMed: 17170110]

37. Saxena V, Sadoqi M, Shao J. Enhanced Photo-Stability, Thermal-Stability and Aqueous-Stability of Indocyanine Green in Polymeric Nanoparticulate Systems. J Photochem Photobiol, B. 2004; 74:29-38. [PubMed: 15043844]

38. Holzer W, Mauerer M, Penzkofer A, Szeimies RM, Abels C, Landthaler M, Baumler W. Photostability and Thermal Stability of Indocyanine Green. J Photochem Photobiol, B. 1998; 47:155-164. [PubMed: 10093915] 

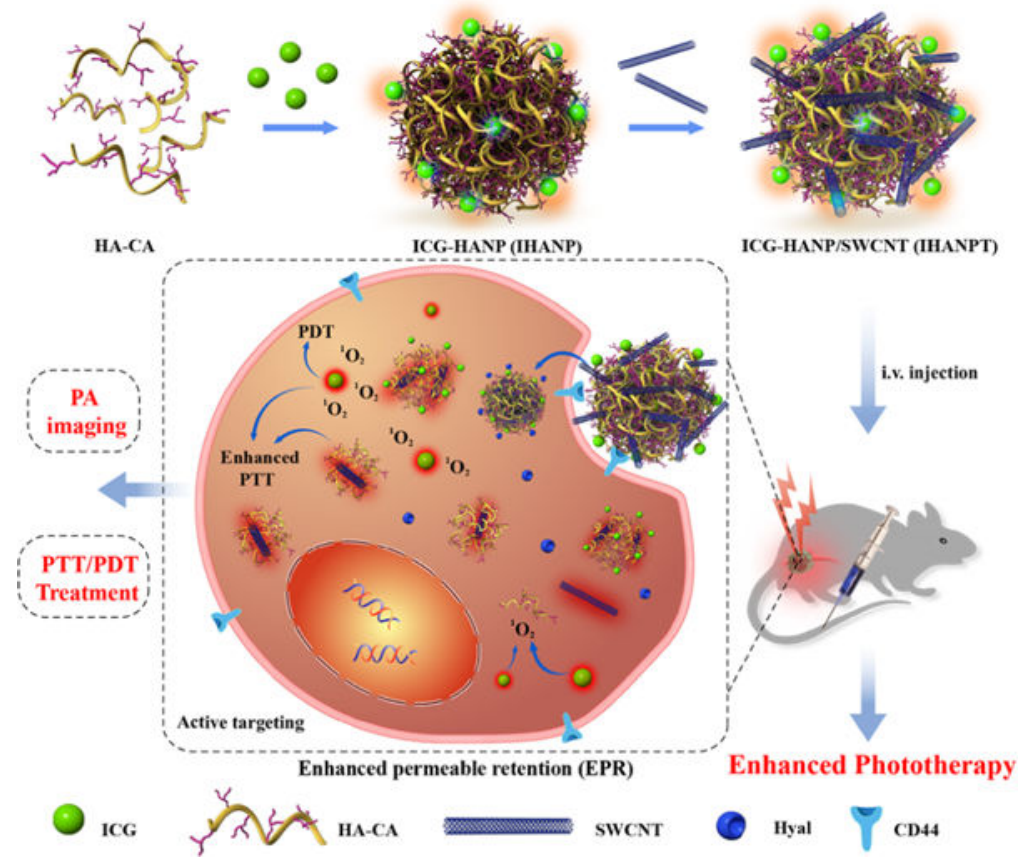

Figure 1.

Design and function of the dual targeted phototherapy agent, Indocyanine Green (ICG)coupled threadlike nanoparticles (IHANPT). 
a

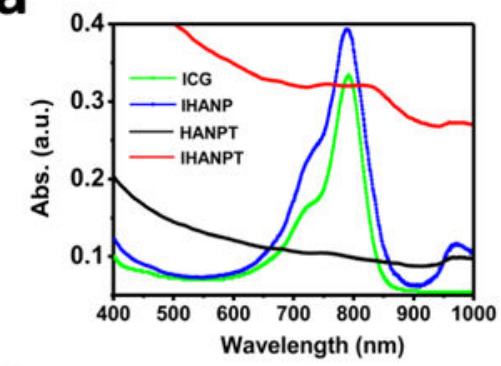

C

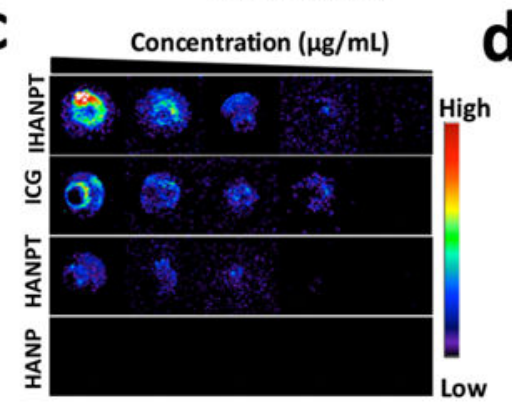

b

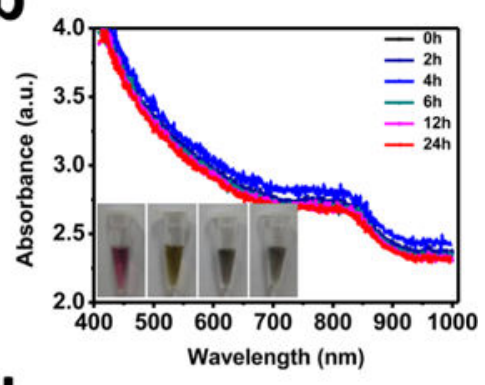

d

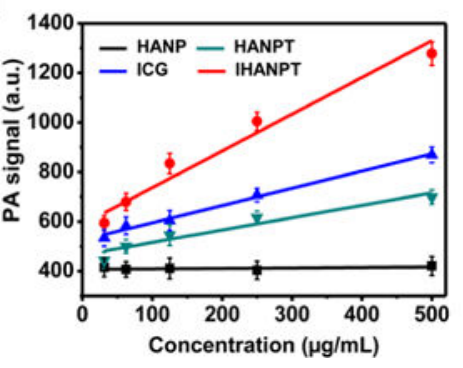

Figure 2.

Characterization of IHNAPT: (a) UV-vis-NIR absorbance spectra of free ICG, IHANP, HANPT, and IHANPT; (b) UV-vis absorbance spectra of IHANPT in darkness at $25^{\circ} \mathrm{C}$ (inset shows the stability of IHANPT in water, PBS, fetal bovine serum (FBS), and cell medium after 2 weeks); (c) PAT images of IHNAPT, HNAPT, free ICG, and HANP at gradient diluted concentrations; and (d) standard curves of PAT signals in IHNAPT, HNAPT, free ICG, and HANP solution at different concentrations. 


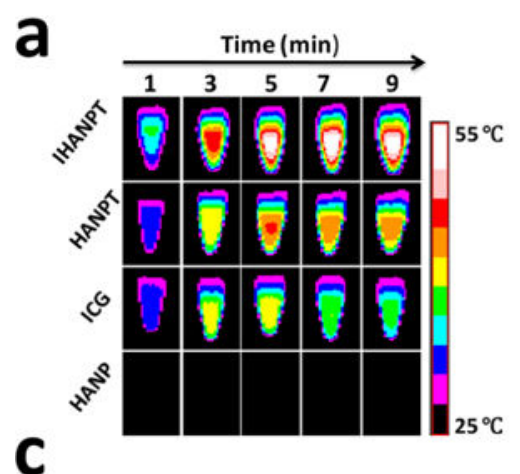

b
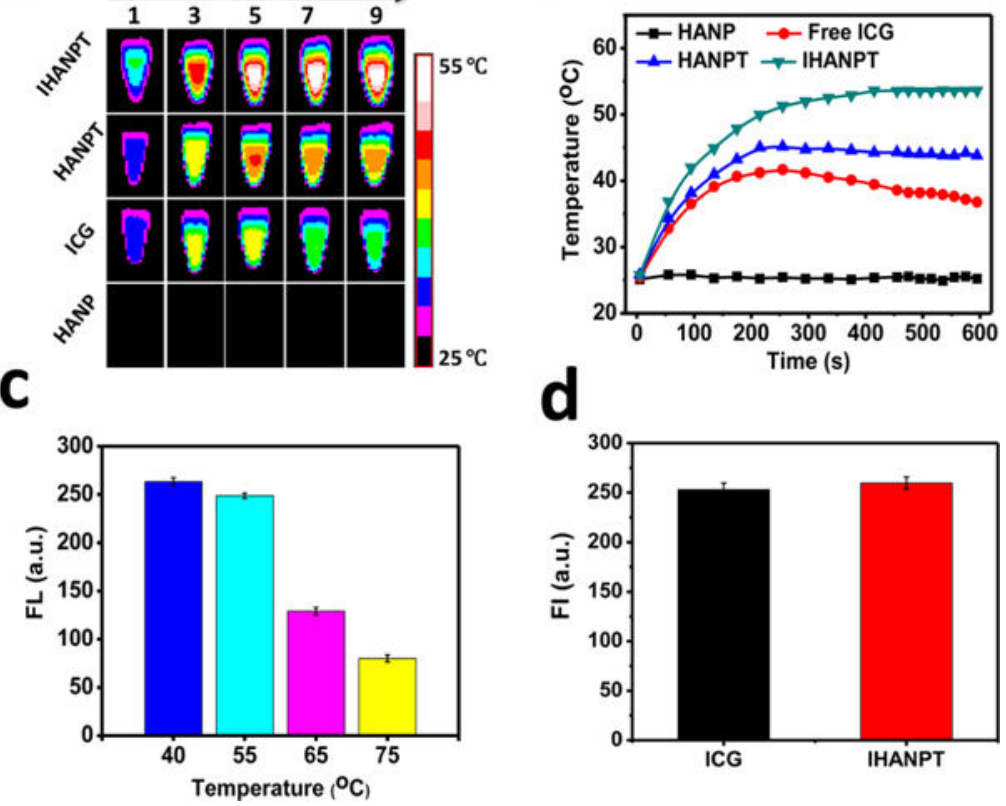

Figure 3.

In vitro photothermal and ${ }^{1} \mathrm{O}_{2}$ generation. (a) Thermal imaging profile of IHANPT, HANPT, ICG, and HANP, as a function of the irradiation time under continuous laser irradiation at a power intensity of $0.3 \mathrm{~W} / \mathrm{cm}^{2}$. (b) Maximum temperature profiles of IHANPT, HANPT, ICG, and HANP, as a function of the irradiation time under continuous laser irradiation at a power intensity of $0.3 \mathrm{~W} / \mathrm{cm}^{2}$. (c) ${ }^{1} \mathrm{O}_{2}$ generation of IHANPT at different temperatures. (d) ${ }^{1} \mathrm{O}_{2}$ generation of IHANP and ICG during single NIR laser irradiation (808 nm laser, light dose rate: $0.3 \mathrm{~W} / \mathrm{cm}^{2}$ ). 
a
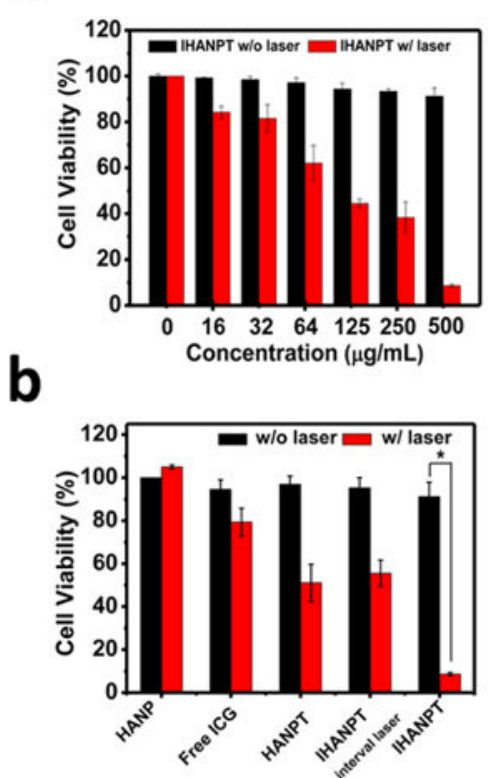

C

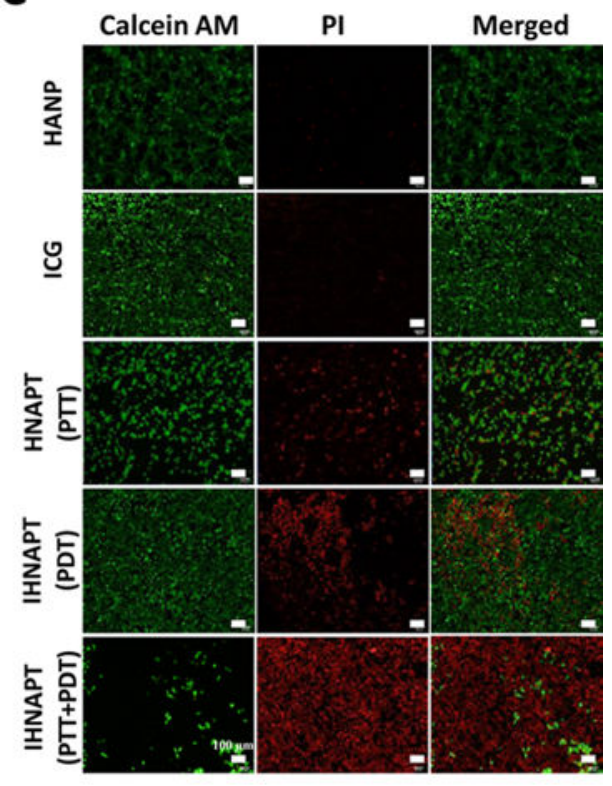

Figure 4.

Cytotoxicity: (a) cell viability studies with IHNAPT at different concentration with or without laser irradiation ( $\left.808 \mathrm{~nm}, 0.3 \mathrm{~W} / \mathrm{cm}^{2}\right)$ on SCC7 cells; (b) cell viability studies with IHANPT (500 $\mu \mathrm{g} / \mathrm{mL}$ IHANPT containing $70 \mu \mathrm{g} / \mathrm{mL}$ of SWCNTs, $16 \mu \mathrm{g} / \mathrm{mL}$ of ICG), HANPT, free ICG, and HANP with laser irradiation $\left(808 \mathrm{~nm}, 0.3 \mathrm{~W} / \mathrm{cm}^{2}\right)$ on $\mathrm{SCC} 7$ cells (asterisk (*) denotes $P<0.05$ ); (c) Calcein AM/PI staining to visualize SCC7 cell viability treated by with IHANPT, HANPT, free ICG with laser irradiation $\left(808 \mathrm{~nm}, 0.3 \mathrm{~W} / \mathrm{cm}^{2}\right.$ for $10 \mathrm{~min})$. Calcein AM (ex/em $=490 / 515 \mathrm{~nm}$ ) staining of live cells is shown in green, and propidium iodide $(\mathrm{PI})(\mathrm{ex} / \mathrm{em}=535 / 615 \mathrm{~nm})$ staining of dead cells is shown in red. 
a

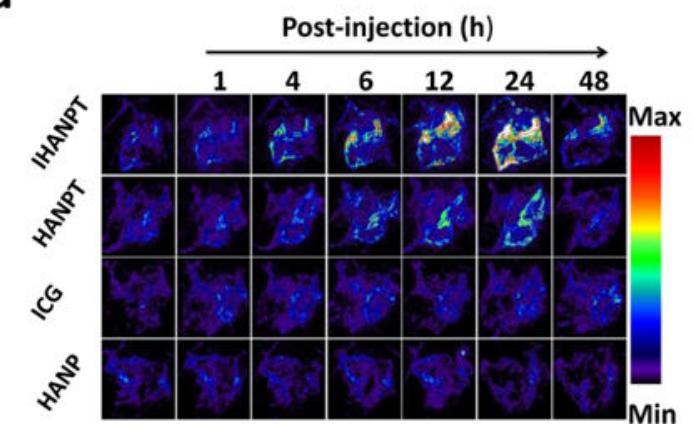

b

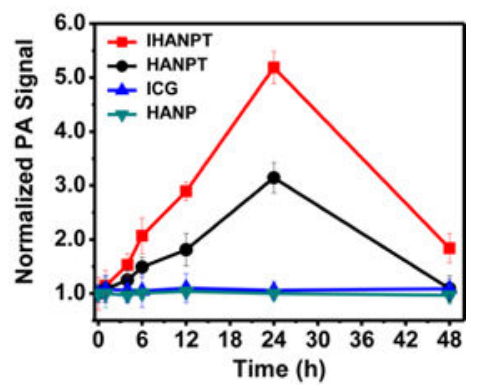

Figure 5.

PA imaging: (a) in vivo PAT imaging of blood vessels in the tumor sites were captured at different time points after intravenous injection of IHANPT, HANPT, free ICG, and HANP; (b) photoacoustic intensity of tumor tissues at different time points. 
a

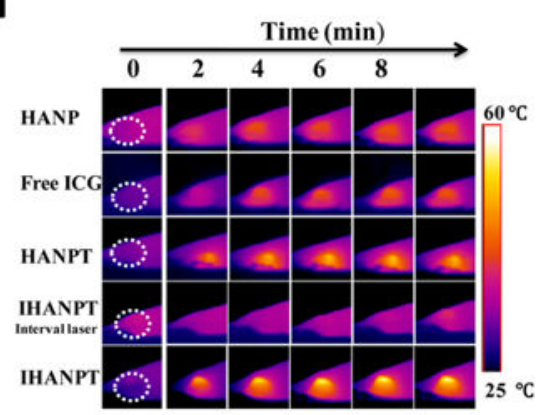

C

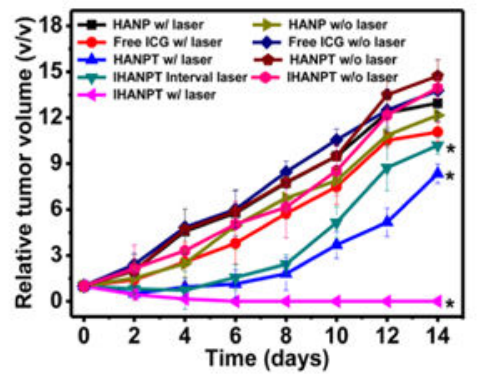

e

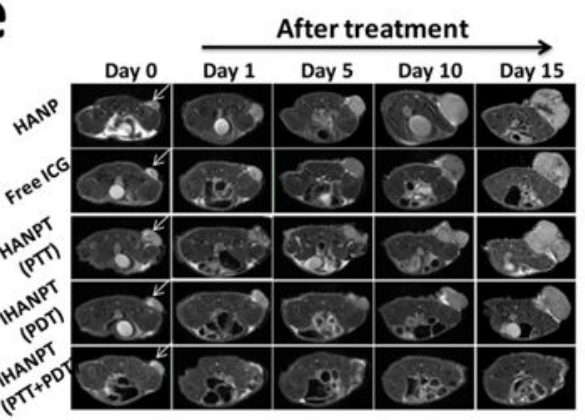

b

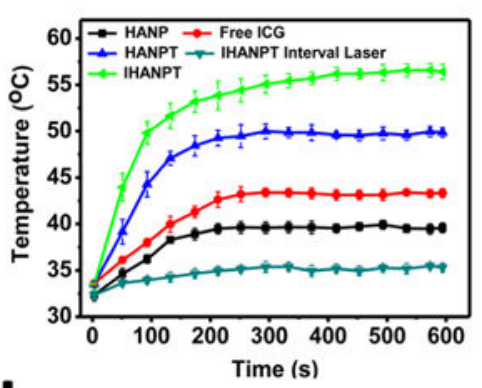

d

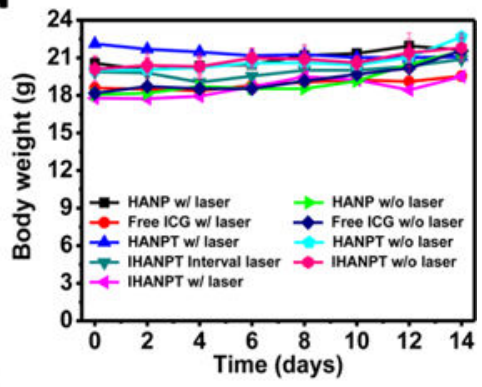

f

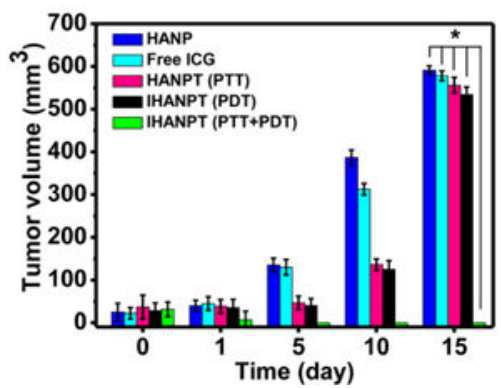

Figure 6.

In vivo phototherapy. (a) Thermal images of SCC7 tumor-bearing mice treated with HANP, free ICG, HANPT, and IHANPT (IHANPT containing $10 \mu \mathrm{g}$ of SWCNTs and $5 \mu \mathrm{g}$ of ICG, $100 \mu \mathrm{L}$ ) with $808 \mathrm{~nm}$ laser illumination at indicated time points. The laser power density was $0.8 \mathrm{~W} / \mathrm{cm}^{2}$. (b) Quantitative analysis of temperature changes in tumor area at different time points. (c) Tumor growth curves of different groups of SCC7 tumor-bearing mice. Error bars represent the standard deviations of three mice per group. (Asterisk $\left(^{*}\right)$ denotes $P<$ 0.05.) (d) Body weights were measured during the 14 day evaluation period in mice under different conditions. Dates indicate means and standard errors. (e) Magnetic resonance imaging (MRI)-monitored therapy response by IHANPT, IHANP, and ICG with laser irradiation. Arrows indicate the locations of tumors. (f) Tumor volume of different groups of SCC7 tumor-bearing mice measured by T2WI MRI after treatments. Error bars represent the standard deviations of three mice per group. (Asterisk $(*)$ denotes $P<0.05$.) 


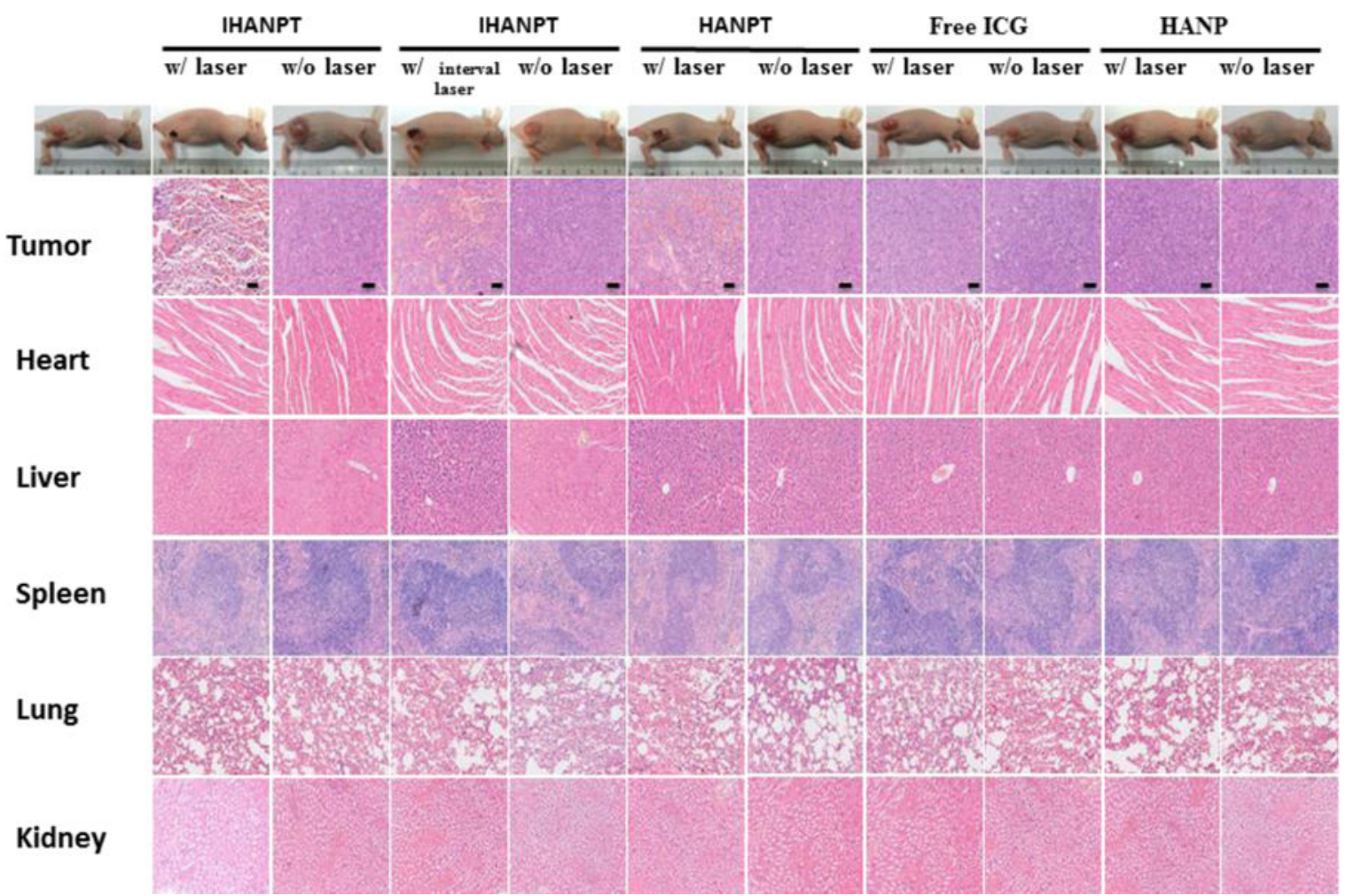

Figure 7.

Histology staining. Hematoxylin and eosin (H\&E) staining of tumors and primary organs of SCC7 tumor-bearing mice treated with IHANPT, HANPT, free ICG, and HANP with or without $808 \mathrm{~nm}$ NIR irradiation. Scale bars $=50 \mu \mathrm{m}$. 


\section{Table 1}

SWCNTs Loading Efficiency under Different Conditions

\begin{tabular}{ccl}
\hline SWCNT:IHANP ratio (wt \%) & loading content $(\%)$ & yield (\%) \\
\hline $1: 9$ & 5.71 & 57.14 \\
$1: 4$ & 14.02 & 70.1 \\
$2: 3$ & 26.00 & 65 \\
\hline
\end{tabular}

